\title{
Ethical Leadership and Whistleblowing: Mediating Role of Stress and Moderating Effect of Interactional Justice
}

\author{
Muhammad Osaid Rabie (D*1; Marlin Abdul Malek (D)2 \\ 1,2 Othman Yeop Abdullah Graduate School of Business, Universiti Utara Malaysia, \\ Malaysia \\ * Corresponding author: osaidrabie@gmail.com
}

\section{Article History \\ Received 2020-03-20 \\ Revised 2020-04-01 \\ Accepted 2020-04-02 \\ Published 2020-04-07}

\section{Keywords}

Ethical Leadership

Whistleblowing

Ethics

stress

\section{How to cite?}

Rabie, M. O., \& Malek, M. A. (2020).

Ethical Leadership and Whistleblowing:

Mediating Role of Stress and Moderating

Effect of Interactional Justice.

SEISENSE Journal of Management,

3(3), 1-11. doi:10.33215/sjom.v3i3.343

Copyright (C) 2020 The Author(s)
Abstract

Purpose- Prevalence of corporate frauds is critical, therefore, identifying and institutionalizing the bad apples in the barrel which are engaged in wrongdoings is much needed and must be brought to the lights through whistleblowing.

Design/Methodology- Data were collected from the South Asian countries through a structured questionnaire from the employees of the telecom sector. Three hundred twenty-nine samples were gathered to test hypothesized relationships.

Findings- Results showed that whistleblowing intentions of employees through psychological stress mediates the behaviors of their leaders, which turns ethical leadership at the workplace. Further, ethical leadership positively impacts employees' intention to blow the whistle at the workplace. Furthermore, the analysis showed that interactional justice moderates the relationship between ethical leadership and intention to blow the whistle of employees

Practical Implications- This research gives a different perspective to the managers to develop such a culture that enables an honest and trustworthy environment, which may enable the employees to point out the wrongdoings they witness while working at the workplace. 


\section{Introduction}

Over the last decades, scholars and theorists have been focusing on the social-psychological research to address wrongdoings at the workplace that causes the significant cost to the organizations, and for this, offered numerous models to address such behaviors (Lei, Ha, \& Le, 2019; Walumbwa et al., 2011). These costs can be corporate scandals framed in media reports or financial embezzlements. They can be reputational in case of filed lawsuits (e.g., misrepresentation and misreporting of financial data, abusive supervision, sexual harassment, theft, or fraud). Such behaviors are incredibly costly as recent statistics have also shown that such behaviors cost 5\% of annual revenue to the organizations (ACFE, 2018). Despite ethical compliance programs, such behaviors are prevalent and challenging to control.

At the workplace, managers act only when employees internally expose wrongdoings at the workplace. Then managers immediately try to identify and get rid of the few bad apples in the barrel, which are engaged in the wrong, and portraying it as a potential consequence for others rather than identifying the cause of such behaviors. Wrongdoings at workplace challenges slightly naive perspective that such behaviors prevail not because of all individuals, but by few bad apples (Kish-Gephart, Harrison, \& Treviño, 2010), as there are people in any organization who cause the problems rather than the system (Chen, 2012). In such circumstances, leadership tries to avoid confrontation and shows little involvement to avoid consequences that may cause them to question their position. So far, existing studies showed how leaders influence and encourage their followers to point out such wrongdoings through voice behavior and whistleblowing, but how leaders get influenced is still needs to be addressed. Therefore, propositions could be the opposite of existing literature, where employees act as pressure that forces their leaders to adopt normative behavior at the workplace. To date, studies typically focus on antecedents of whistleblowing, but not on the potential consequences of such behaviors.

So far, existing literature showed ethical judgment (Chiu, 2003), moral reasoning (Liyanarachchi \& Newdick, 2009), and ethical environment (Dalton \& Radtke, 2013) as antecedents of whistleblowing. Recent research has significantly enhanced our understanding of behavioral ethics in the workplace. It has explained the different mechanisms, in the context of leadership, ethical leadership positively associated with psychological ownership (Avey, Wernsing, \& Palanski, 2012), cognitive and affective trust (Lu, 2014), moral attentiveness (Rabie \& Malek, 2020) job autonomy (Kalshoven, Den Hartog, \& de Hoogh, 2013), job satisfaction (Kim \& Brymer, 2011), meaningfulness (Mostafa \& Abed El-Motalib, 2020) and whistleblowing. However, the factors through which ethical leadership gets influenced are still limited and fragmented. For these reasons, this research explains the mediating mechanisms that study the pressure of whistleblowers' that can potentially influence the behavior of leaders to act ethically at the workplace. Through the conservation of resource theory (Hobfoll, 1989), we propose that whistleblowers can act as pressure/force to influence the ethical behavior of leadership at the workplace. To get better insights of phenomenon, explaining the mediating mechanisms provides better understating for designing organizational ethical and compliance programs to stimulate ethical behavior of employees (Brown \& Treviño, 2006; Moore et al., 2019). For this reason, we propose that psychological stress mediates the relationship of whistleblowing on ethical leadership behavior.

The current study thus contributes to the literature of behavioral ethics in multiple ways. Firstly, the conservation of resource theory compliments this study, perhaps for the first time, to explain the impact of whistleblowers via psychological stress. Exploring the alternative mediation mechanisms would help in understating the underlying process at work. Examining the whistleblowing intention towards their leaders is also useful in that it may help the upper echelon in formulating policies and stimulating ethical behavior. Second, according to the author's knowledge, the current study is first of its nature, which suggests the effect of whistleblower on leaders' ethical behaviors. Thirdly, this study also suggests ethical leadership may influence the whistleblowing intentions of his/her followers. Moreover, this study will also study the moderating impact 
of interactional justice on ethical leadership and whistleblowing intentions. We will start with a theoretical framework and later finish with some discussion.

\section{Literature Review and Hypothesis}

\section{Impact of Whistleblowing on Ethical Leadership Behavior via Psychological Stress}

Conservation of resource theory posits that when individuals are not dealing with stressors, they tend to develop resource surpluses to minimize the chances of future losses (Hobfoll, 1989). Individuals try to get and maintain the resources to overcome threats, withstand, and to accommodate. They may also try to gain different resources, for instance, condition support: social support and status, material support: money, and personal support: self-esteem (Hobfoll, 1989).

Furthermore, the theory argues that the extent to which conditions are valued by individuals or groups may try to adopt certain behaviors that are having stress-resistance potential. Whenever individuals feel that their resources are depleting, they tend to resolve it at any imminent demand. Notably, in the case of actual depletion of the resource, for example, loss of status or money, they start experiencing actual stress (Hobfoll, 1989). On the other hand, in the case when resources are under threat, for instance, when individuals are in a condition that they may lose status or money, then it leads them to psychological stress (Hobfoll, 1989). However, individuals always try to save the resources they have attained over some time. We suggest that whistleblowing is quite a risky for a subordinate (Miceli, Rehg, Near, \& Ryan, 1999), and it is often not in the interest of leaders in the organizations as they are the one who enjoys status, reputation and other monetary rewards more than their subordinates. This is because individuals try to maintain and enhance self-worth and self-esteem at top positions (Shamir, 1991), which is built from their acquired resources (social status, power, self-concept, etc.) (Gecas, 1982).

Furthermore, individuals having a higher level of self-esteem also tend to avoid stress and negative feedback (Li, Arvey, \& Song, 2011). And whenever leaders/supervisors feel threatened towards any of the acquired resources (status, reputation, social support, etc.) and foresee any threat may hit their self-esteem, they tend to try to avoid the situation as much as possible. As they are considered a role model in the organization, and when any of the employees blow the whistle, resources gathered by the leaders start depleted, and they get stressed. However, stress is a factor that is more likely to affect the moral actions of individuals. It may affect individuals' pro-social behavior from two mechanisms. Firstly, it is more likely to adopt antagonistic stance by the people who are under stress (Cooper, Dewe, \& O'Driscoll, 2001). The assertive stress comes in the form of aggressive behavior that may lead to reduce the pro-social orientation of people (Dépret \& Fiske, 1999). The second one is that they get stress and tries to hold on the fight to fight response. To retain their resources, they start behaving at normative behavior, which may lead to ethical behavior of leadership at the workplace. Accordingly, we propose that:

\section{Hypothesis 1: Stress mediates the relationship between whistleblowing intentions and ethical leadership behavior.}

\section{Impact of Ethical Leadership on Whistleblowing Intentions}

Ethical leadership is "the demonstration of normatively appropriate conduct through personal actions and interpersonal relationships, and the promotion of such conduct to followers through two-way communication, reinforcement, and decision-making" (Brown, Treviño, \& Harrison, 2005). Treviño, Hartman, and Brown (2000) showed two aspects on which the reputation of ethical leaders' rests, which includes moral person and moral manager. Ethical leaders, as a moral person, have a responsibility is to conform with normative behavior. Ethical leaders are considered ones that stimulate some personality traits and normative behavior in professional and personal lives (McCann \& Holt, 2009). These normative behaviors and personality traits are "good compass" to provide them not only with a good sense of direction but also enable them to guide their followers. 
In the case of moral managers, ethical leaders create principles and codes for their followers. It is required from ethical leaders to have a keen awareness of ethical issues while exhibiting ethical behavior (Toor \& Ofori, 2009), because, in the position of leadership, managerial skills are expected from them to direct employees' attention on ethical dilemmas (Treviño et al., 2000).

From these arguments, we posit that ethical leaders are primarily required to advocate and formulate moral concerns and principles. They also expected to develop a sustainable employer-employee relationship (Brown et al., 2005). It is quite conceivable that whistleblowing can retaliate, and individuals who blow the whistle are familiar with the associated risk; whistleblowers are confident about support, trustworthiness, and ethicality of management (Brockner, Siegel, Daly, Tyler, \& Martin, 1997). Whistleblowers have external and internal channels for reporting any transgressions. Research showed that before going to external channels, whistleblowers attempt to highlight the issue internally (Miceli \& Near, 2002). Even though whistleblowing is less threatening for the organizations via internal channels, however, their reporting of wrongdoing often goes unnoticed or buried (Miceli, Near, \& Schwenk, 1991). Literature also showed that whistle is likely to be blown regarding the wrongdoings within workgroup that have supportive leadership and principle-based environment (Graham, 1991). It is evident that ethical leadership creates a trustworthy, honest, and principle-based environment, and due to this, the employee can blow the whistle without having a fear of being caught, retaliation, or punished. For these reasons, we expect that such a supportive stance provided by ethical leaders can encourage whistleblowing on any wrongdoing employees may witness while performing their duties at the workplace (Finn, 1995). Hence, the authors propose:

\section{Hypothesis 2: Ethical leaders positively influence employee whistleblowing intention.}

\section{Interactional Justice as moderator}

Interactional justice emphasizes interpersonal interaction or treatment that individuals experience from implementing justice (Bies \& Moag, 1986). It incorporated two dimensions (1) the degree to which individuals get treated with respect, dignity, and politeness; and (2) the descriptions provided that deliver information regarding the outcomes/procedures were distributed in the prescribed way (Greenberg, 1987, 1990). Interactional justice gives employees a sense of trustworthiness that weakens their managerial and social pressure (Stinglhamber, De Cremer, \& Mercken, 2006). Interactional justice serves as an exchange mechanism concerning the relationship of the employer with the employee (Cropanzano, Prehar, \& Chen, 2002). Because interactional justice engenders higher employer-employee exchange relationships (Masterson, Lewis, Goldman, \& Taylor, 2000), which affects the behavior of employees (Stecher \& Rosse, 2005). We expect that employees will positively take the actions of leaders and may reciprocate for the welfare of the workplace and community and raise their voices by either to their immediate supervisor or top management leadership regarding any wrongdoing they see at the workplace.

Moreover, when followers observe interactional justice, they perceive that their supervisor treats them fairly and respectfully. This treatment of fairness will continue to be perceived by employees and their intention to blow the whistle in favor of their organizations, unless and until they suffer any negative stimulus (Lind, 2001). Besides, when supervisors satisfy the employees' perceptions of the organization's responsibilities and build interpersonal relationships, employees' trust in their leaders will grow (Whitener, 1998). Subsequently, employees' higher interactional justice will show the higher value of ethical leadership. When they experience normative behavior of the leaders because this fairness and respect (Cropanzano et al., 2002) give them a signal to reciprocate the inducement and to raise their voice if they see any wrongdoing at the workplace. Therefore, we propose that high interactional justice may positively increase the effects of ethical leadership on whistleblowing intentions. For this, current research proposes: 
Hypothesis 4: Interactional justice positively moderates the strength of the relationship between etbical leadership and whistleblowing intention.

\section{Methods and Data Analysis}

\section{Procedure and Sample}

For this study, the survey method was used for data collection purposes from employees of private and public telecommunication organizations of Pakistan. We contacted their human resource department for approval regarding data collection after explaining the objectives of our study. In this research, employees are of the functional and non-managerial level. The author personally visits the organization to gather data from respondents. To minimize the social desirability bias, the authors paid attention to that respondents remain anonymous and confidential (Chung \& Monroe, 2003). The response rate varied from $16 \%$ to $96 \%$. A total of 329 questionnaires were received, 15 were discarded as they have a large number of missing values, which made a total 314 usable questionnaires for data analysis. Out of 314 respondents, $75 \%$ were male. Most respondents were from a relatively young age group: 85\% (267) was less than 40 years of age. Around $71.7 \%$ of respondents were below functional management positions (lower management), and $28.3 \%$ of respondents were engaged in functional-level job responsibilities.

\section{Measures}

The ethical leadership of the employees was measured in different departments. We used the ten-item scale of Brown et al. (2005). A sample item is: "My immediate supervisor listens to what employees have to say." Interactional justice will be measured by adopting the 9-item scale developed by Colquitt (2001). Sample items include "Has (he/she) treated you with respect?" and "Were (his/her) explanations regarding the procedures reasonable?". Whistleblowing intentions were measured by a 4-item scale developed by Park and Blenkinsopp (2009). Psychological stress was measured using a 13-item scale. A sample question, "I have felt fidgety or nervous as a result of my job" (Parker \& DeCotiis, 1983).

\section{Results}

\section{Confirmatory Factor Analysis and Measurement Validity}

To test model validity, we conducted a CFA with AMOS 24. For assessing the validity of the proposed model, we computed three alternative models and compared their level of fit (Anderson \& Gerbing, 1988): First (Table 1), all items belong to the four constructs were loaded on a single factor (Model 1). Second, we computed a three-factor CFA regrouping the construct in a single construct (Model 2). Finally, we assessed the fit of a fourfactor CFA (Model 3).

Whereas Models 1 and 2 returned a poor fit; however, the fit of the four-factor CFA is satisfactorily presented in Table 1. The chi-square statistic is 481.97, p. <.001 and 195 degrees of freedom (2.47), showing the good fit of the model (Kline, 2015). We examined two incremental fit indices: The Tucker-Lewis index (TLI) is .95, and the Confirmatory Fit Index (CFI) is .96, both are higher than their recommended levels. Additionally, root mean square error of approximation (RMSEA) is lower than (Table 1) the acceptable threshold of .08 (Anderson \& Gerbing, 1988). The chi-square difference test (Table 1) revealed that the Model 3 (Table 1) showed good fit indices as compared to other alternative models (Model 1 and Model 2). Results confirmed and showed no validity issues regarding our proposed model and data. 


\begin{tabular}{lllllll}
\hline & \multicolumn{2}{l}{ Fit Indices } & & & \\
\cline { 2 - 7 } Model & $\chi^{2}$ & $\mathrm{df}$ & $\chi^{2} / \mathrm{df}$ & CFI & TLI & RMSEA \\
Model 1: Single-Factor CFA & 3189.21 & 209 & 15.25 & .50 & .42 & .20 \\
Model 2: Three-Factor CFA & 2001.45 & 206 & 9.71 & .62 & .71 & .13 \\
Model 3: Four-Factor CFA & 481.97 & 195 & 2.47 & .95 & .96 & .06 \\
\hline
\end{tabular}

$\chi^{2}$ Chi-square value, $d f$ degree of freedom,

Then, to assess convergent validity, the authors analyzed the standardized regression weights of all items. For all items, standardized regression weights ranged between .67 and .92. Kline (2015), reported that a standardized value higher than .60 demonstrates a reasonably high factor loading. To more fully assess the discriminant validity of the four factors in our model, we followed Fornell and Larcker (1981) procedure and compared the respective squared correlations between factors with the respective AVEs of the factors. Through this method, the problem of difference in chi-square can be resolved. The four variables are distinctive, as the AVE belongs to four factors, as shown in Table 2 are more substantial than their squared correlations.

For internal consistency and reliability (Table 2), we relied on Cronbach's alpha. These scales showed internal consistency and reliability with values for all variables ranging from .85 to .91 , higher than the acceptable value of .70 (Nunnally, 1978).

Table 2 - Convergent and discriminant validity

\begin{tabular}{lccccl}
\hline Constructs & $\mathbf{1}$ & $\mathbf{2}$ & $\mathbf{3}$ & $\mathbf{4}$ & Cronbach's Alpha \\
\hline 1. Ethical Leadership & $\mathbf{. 6 5}$ & & & & .91 \\
2. Stress & .33 & .71 & & .85 \\
3. Whistleblowing & .37 & .18 & .63 & .91 \\
4. Interactional Justice & .32 & .11 & .25 & .64 & .89 \\
\hline
\end{tabular}

Notes: bold values are AVE, Other values: squared correlations

To assess common method bias, a common latent factor test was applied (Podsakoff, MacKenzie, Lee, \& Podsakoff, 2003). For conducting the common latent factor test, the authors used CFA and constrained all the items for all dependent and independent variables to load on a single factor. It was concluded that the model only explained $29.16 \%$ of the common factor, which is not higher than the threshold value. Therefore, these results indicate that in our data, standard method bias is not a severe threat.

\section{Hypothesis Testing}

The structural equation modeling platform was adopted for analyzing the structural regression model (indirect effect: bootstrapping in AMOS 24 and moderating effects: Orthogonalization, Figure 1) simultaneously. To do so, we followed the orthogonalized approach to test the interaction effect in structural equations (Little, Bovaird, \& Widaman, 2006). Little et al. (2006) use observed covariation patterns among all possible indicators of interaction for testing the moderation effect by creating a latent interaction term. We then directly included interaction latent variable and its measure in our model. This model (Model 1) produces a good fit $(\chi 2=1689.5$, $\mathrm{df}=738, \chi 2 / \mathrm{df}=2.289 ; \mathrm{CFI}=.94 ; \mathrm{TLI}=.93 ; \mathrm{RMSEA}=.05)($ see Model 1 in Table 3$)$. In pursuit of the bestfit model, we compare the two possible alternative structural regression models with our hypothesized model (Table 3), which shows that our proposed model (Table 3; Model 1) reports a better fit as compared to the other. Therefore, we select this model 1 for the interpretation of the results. 
Table 3 - Fit indices of the structural models

\section{Model}

Model 1: Hypothesized Model

Alternative Models

Model 2: EL $\rightarrow$ PS $\rightarrow$ WB

Model 3: PS $\rightarrow$ WB $\rightarrow$ EL

\begin{tabular}{llllll}
\multicolumn{6}{c}{ Fit Indices } \\
\hline$\chi^{2}$ & $d f$ & $\chi^{2} / d f$ & CFI & TLI & RMSEA
\end{tabular}

$\begin{array}{llllll}1689.5 & 738 & 2.289 & 0.94 & 0.93 & 0.05\end{array}$

$\begin{array}{llllll}812.44 & 270 & 4.52 & .90 & .89 & .08\end{array}$

$\begin{array}{llllll}509.57 & 196 & 2.61 & .88 & .90 & .08\end{array}$

There is a positive impact of whistleblowing intentions on ethical leadership via psychological stress $(\beta=0.16$, $\mathrm{p}<.001$, Figure 1). Similarly, ethical leadership positively and significantly effecting whistleblowing intentions $(\beta=0.37, \mathrm{p}<.001$, Figure 1$)$. Hypothesis 3 stipulated that interactional justice moderates between ethical leadership and whistleblowing intentions. Our results provided support for Hypotheses $3(\beta=0.11, \mathrm{p}<.01$, Figure 1). The data support Hypotheses 1, 2, and 3 (see Figure 1).

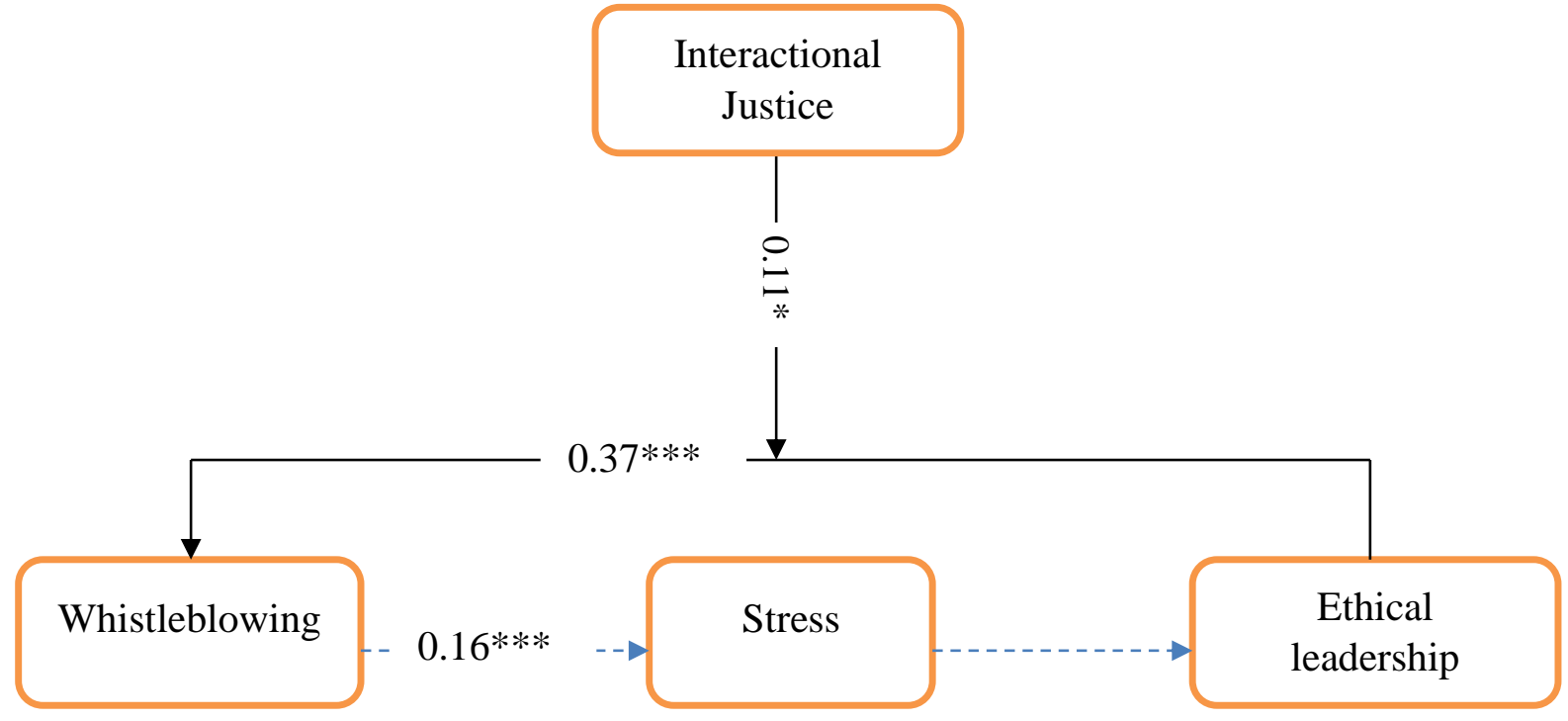

Figure 1 - Hypothesized Framework

\section{Discussion and conclusion}

The proposed theoretical model describes the significance of considering whistleblowing in an organization that is stimulated by the pressures of social actors. We are proposing a new perspective by integrating the conservation of resource theory to elucidate the association of employees' whistleblowing intentions with ethical leadership behavior at work. To summarize, we have argued whistleblowing can influence the ethical behavior of leadership through the mediating mechanism of psychological stress. Results showed that while working, leaders are the ones who have to answer stakeholders regarding their decisions. They are the ones who are answerable, and due to this fact, they stressed out when anything is going to hurt their earned resources or fear of being spotted if the whistle is blown, they start adopting ethical practices. Because if they do not portray themselves as ethical leaders, they may lose their status and social standing that they have earned (Lin, Ma, \& Johnson, 2016). We further argued, and results showed that ethical leadership could also influence the whistleblowing intentions of its followers.

On one hand where leaders through the whistleblowing intentions from employee feel psychological stress and try to adopt normative behavior, but conversely, it is also essential that ethical leadership is not all about being 
ethical people, they also have to stimulate normative behavior by encouraging and supporting their followers. They are the one who set the standards as they are one who is legitimate role models (Treviño et al., 2000). Ethical leadership is the one who sticks to their ethical values by supporting their followers to act ethically without fear of anyone and to blow the whistle on every wrongdoing they witness at the workplace. This side of ethical leadership is essential from the perspective of whistleblowing that shows a higher risk of retaliation, both by individual/group or by organizations against whom the whistle is blown.

Furthermore, the current study also explained the moderation of interactional justice in a way that moderates the relationship between ethical leadership and whistleblowing intentions in organizations. It explains that from ethical leaders, followers get the impression that their leaders are honest and trustworthy, which enables them to blow the whistle when they see anything going against the interest of their organization. This behavior in employees comes from the interaction they have at the workplace. And through such interactions, they feel a sense of trustworthiness and fairness that enables then to have confidence while reporting any wrongdoing. Thus, when employees feel interactional justice, the existing relationship becomes more robust as our results also showed during the analysis. This study provides insights related to the employee-employer relationship that enables the researchers and practitioners to study their impacts from different theoretical lenses.

Extant literature has documented a growing interest in exploring whistleblowing intentions and leadership behaviors (Bhal \& Dadhich, 2011; Liu, Liao, \& Wei, 2015). However, quite a few studies have provided from the perspective of ethical leadership on individual and organizational outcomes, for instance, individual outcomes (knowledge sharing, affective commitment and turnover intention of employees), and organization outcomes (corporate social responsibility, firm performance) from maintaining ethical culture in the organization (Demirtas \& Akdogan, 2015; Lei et al., 2019; Wu, Kwan, Yim, Chiu, \& He, 2015). It is evident that whistleblowing intentions are more prevailing in higher ethical climate (Finn, 1995); the authors posit the mechanism of psychological stress to elucidate the proposed relationship. This provides a much-needed contribution to the field of whistleblowing and ethical leadership literature.

\section{Future Directions and Limitations}

This study was conducted in South Asia, where standards, values, national culture, traditions, and regulations are different from Western countries. Even though our proposed model is theoretically driven, and results are generalizable in most situations, the strength of relationships drawn in this research may differ in other cultural environments and in Western or developed economies. Furthermore, we took precautions to address social desirability bias and common method variance (for example, well-established scales, survey's instruction and structure, confidentiality, and anonymity), all the constructs measured through the self-reported survey. Although, all measures in this research reflect individual-level cognition and perception. Though self-reported surveys are considered useful and valid approaches for evaluating the attitudes, feelings, and perceptions of individuals (Glick, Jenkins Jr, \& Gupta, 1986). Podsakoff and Organ (1986) also demonstrated that individuals provide responses to ongoing organizational events quite accurately. However, this study employed the method of Podsakoff et al. (2003) the common latent factor test to minimize the threats of common method bias. Moreover, this study adopted a cross-sectional design; we encourage future research to adopt a longitudinal research design integrating constructs for multiple sources in order to support the causality of observed relationships and to minimize potential bias.

Funding: This research received no external funding.

Conflicts of Interest: The authors declare no conflict of interest. 


\section{References}

ACFE. (2018). Report to the nations: 2018 Global study on occupational fraud and abuse. Retrieved from https://s3-uswest-2.amazonaws.com/acfepublic/2018-report-to-the-nations.pdf

Anderson, J. C., \& Gerbing, D. W. (1988). Structural equation modeling in practice: A review and recommended two-step approach. Psychological bulletin, 103(3), 411.

Avey, J. B., Wernsing, T. S., \& Palanski, M. E. (2012). Exploring the process of ethical leadership: The mediating role of employee voice and psychological ownership. Journal of Business Ethics, 107(1), 21-34.

Bhal, K. T., \& Dadhich, A. (2011). Impact of ethical leadership and leader-member exchange on whistle blowing: The moderating impact of the moral intensity of the issue. Journal of Business Ethics, 103(3), 485. doi:10.1007/s10551-011-0876-z

Bies, R. J., \& Moag, J. S. (1986). Interactional justice: Communication criteria of fairness. Research on Negotiation in Organizations, 1, 43-55.

Brockner, J., Siegel, P. A., Daly, J. P., Tyler, T., \& Martin, C. (1997). When trust matters: The moderating effect of outcome favorability. Administrative Science Quarterly, 558-583.

Brown, M. E., \& Treviño, L. K. (2006). Ethical leadership: A review and future directions. The Leadership Quarterly, 17(6), 595-616.

Brown, M. E., Treviño, L. K., \& Harrison, D. A. (2005). Ethical leadership: A social learning perspective for construct development and testing. Organizational Behavior and Human Decision Processes, 97(2), 117-134.

Chiu, R. K. (2003). Ethical judgment and whistleblowing intention: Examining the moderating role of locus of control. Journal of Business Ethics, 43(1), 65-74.

Chung, J., \& Monroe, G. S. (2003). Exploring social desirability bias. Journal of Business Ethics, 44(4), $291-302$.

Colquitt, J. A. (2001). On the dimensionality of organizational justice: A construct validation of a measure. Journal of Applied Psychology, 86(3), 386-400. doi:10.1037/0021-9010.86.3.386

Cooper, C. L., Dewe, P. J., \& O'Driscoll, M. P. (2001). Organizational stress: A review and critique of theory, research, and applications: Sage.

Cropanzano, R., Prehar, C. A., \& Chen, P. Y. (2002). Using social exchange theory to distinguish procedural from interactional justice. Group \& Organization Management, 27(3), 324-351.

Dalton, D., \& Radtke, R. R. (2013). The joint effects of Machiavellianism and ethical environment on whistleblowing. Journal of Business Ethics, 117(1), 153-172.

Demirtas, O., \& Akdogan, A. A. (2015). The effect of ethical leadership behavior on ethical climate, turnover intention, and affective commitment. Journal of Business Ethics, 130(1), 59-67.

Dépret, E., \& Fiske, S. T. (1999). Perceiving the powerful: Intriguing individuals versus threatening groups. Journal of Experimental Social Psychology, 35(5), 461-480.

Finn, D. (1995). Ethical decision making in organizations: A management employee-organization whistleblowing model. Research on Accounting Ethics, 1(1), 291-313.

Fornell, C., \& Larcker, D. F. (1981). Structural equation models with unobservable variables and measurement error: Algebra and statistics. Journal of marketing research, 18(3), 382-388.

Gecas, V. (1982). The self-concept. Annual review of sociology, 8(1), 1-33.

Glick, W. H., Jenkins Jr, G. D., \& Gupta, N. (1986). Method versus substance: How strong are underlying relationships between job characteristics and attitudinal outcomes? Academy of Management journal, 29(3), 441-464. doi:10.5465/256218

Graham, J. W. (1991). An essay on organizational citizenship behavior. Employee Responsibilities and Rights Journal, 4(4), 249-270.

Greenberg, J. (1987). A taxonomy of organizational justice theories. Academy of management review, 9-22.

Greenberg, J. (1990). Organizational justice: Yesterday, today, and tomorrow. Journal of management, 16(2), 399432. 
Hobfoll, S. E. (1989). Conservation of resources: A new attempt at conceptualizing stress. American psychologist, 44(3), 513.

Kalshoven, K., Den Hartog, D. N., \& de Hoogh, A. H. (2013). Ethical leadership and followers' helping and initiative: The role of demonstrated responsibility and job autonomy. European journal of work and organizational psychology, 22(2), 165-181.

Kim, W. G., \& Brymer, R. A. (2011). The effects of ethical leadership on manager job satisfaction, commitment, behavioral outcomes, and firm performance. International Journal of Hospitality Management, 30(4), 10201026.

Kish-Gephart, J. J., Harrison, D. A., \& Treviño, L. K. (2010). Bad apples, bad cases, and bad barrels: Metaanalytic evidence about sources of unethical decisions at work. Journal of Applied Psychology, 95(1), 1-31. doi: $10.1037 / \mathrm{a} 0017103$

Kline, R. B. (2015). Principles and practice of structural equation modeling: Guilford publications.

Lei, H., Ha, A. T. L., \& Le, P. B. (2019). How ethical leadership cultivates radical and incremental innovation: the mediating role of tacit and explicit knowledge sharing. Journal of Business \& Industrial Marketing. doi:doi:10.1108/JBIM-05-2019-0180

Li, W.-D., Arvey, R. D., \& Song, Z. (2011). The influence of general mental ability, self-esteem and family socioeconomic status on leadership role occupancy and leader advancement: The moderating role of gender. The Leadership Quarterly, 22(3), 520-534.

Lin, S.-H., Ma, J., \& Johnson, R. E. (2016). When ethical leader behavior breaks bad: How ethical leader behavior can turn abusive via ego depletion and moral licensing. Journal of Applied Psychology, 101(6), 815830. doi:10.1037/apl0000098

Lind, E. A. (2001). Fairness heuristic theory: Justice judgments as pivotal cognitions in organizational relations. Advances in organizational justice, $56,88$.

Little, T. D., Bovaird, J. A., \& Widaman, K. F. (2006). On the Merits of Orthogonalizing Powered and Product Terms: Implications for Modeling Interactions Among Latent Variables. Structural Equation Modeling: A Multidisciplinary Journal, 13(4), 497-519. doi:10.1207/s15328007sem1304_1

Liu, S.-m., Liao, J.-q., \& Wei, H. (2015). Authentic leadership and whistleblowing: Mediating roles of psychological safety and personal identification. Journal of Business Ethics, 131(1), 107-119.

Liyanarachchi, G., \& Newdick, C. (2009). The impact of moral reasoning and retaliation on whistle-blowing: New Zealand evidence. Journal of Business Ethics, 89(1), 37-57.

Lu. (2014). Ethical leadership and organizational citizenship behavior: The mediating roles of cognitive and affective trust. Social Behavior and Personality: an international journal, 42(3), 379-389.

Masterson, S. S., Lewis, K., Goldman, B. M., \& Taylor, M. S. (2000). Integrating justice and social exchange: The differing effects of fair procedures and treatment on work relationships. Academy of Management journal, 43(4), 738-748.

McCann, J., \& Holt, R. (2009). Ethical leadership and organizations: An analysis of leadership in the manufacturing industry based on the perceived leadership integrity scale. Journal of Business Ethics, 87(2), 211-220.

Miceli, M. P., \& Near, J. P. (2002). What makes whistle-blowers effective? Three field studies. Human Relations, 55(4), 455-479.

Miceli, M. P., Near, J. P., \& Schwenk, C. R. (1991). Who blows the whistle and why? ILR Review, 45(1), 113130.

Miceli, M. P., Rehg, M., Near, J. P., \& Ryan, K. C. (1999). Can laws protect whistle-blowers? Results of a naturally occurring field experiment. Work and occupations, 26(1), 129-151.

Moore, C., Mayer, D. M., Chiang, F. F. T., Crossley, C., Karlesky, M. J., \& Birtch, T. A. (2019). Leaders matter morally: The role of ethical leadership in shaping employee moral cognition and misconduct. Journal of Applied Psychology, 104(1), 123-145. doi:10.1037/ap10000341 
Mostafa, A. M. S., \& Abed El-Motalib, E. A. (2020). Ethical leadership, work meaningfulness, and work engagement in the public sector. Review of Public Personnel Administration, 40(1), 112-131. doi:10.1177/0734371x18790628

Nunnally, J. C. (1978). Psychometric theory (2nd ed.). New York: McGraw-Hill.

Park, H., \& Blenkinsopp, J. (2009). Whistleblowing as Planned Behavior - A Survey of South Korean Police Officers. Journal of Business Ethics, 85(4), 545-556. doi:10.1007/s10551-008-9788-y

Parker, D. F., \& DeCotiis, T. A. (1983). Organizational determinants of job stress.

Podsakoff, P. M., MacKenzie, S. B., Lee, J.-Y., \& Podsakoff, N. P. (2003). Common method biases in behavioral research: A critical review of the literature and recommended remedies. Journal of Applied Psychology, 88(5), 879-903.

Podsakoff, P. M., \& Organ, D. W. (1986). Self-reports in organizational research: Problems and prospects. Journal of management, 12(4), 531.

Rabie, M. O., \& Malek, M. A. (2020). Ethical Leadership and Employee Ethical Behavior: A Moderated Mediation Mechanisms. SEISENSE Journal of Management, 3(2). doi:10.33215/sjom.v3i2.321

Shamir, B. (1991). Meaning, self and motivation in organizations. Organization Studies, 12(3), 405-424.

Stecher, M. D., \& Rosse, J. G. (2005). The distributive side of interactional justice: The effects of interpersonal treatment on emotional arousal. Journal of Managerial Issues, 229-246.

Stinglhamber, F., De Cremer, D., \& Mercken, L. (2006). Perceived Support as a Mediator of the Relationship Between Justice and Trust A Multiple Foci Approach. Group \& Organization Management, 31(4), 442-468.

Toor, S. U. R., \& Ofori, G. (2009). Authenticity and its influence on psychological well-being and contingent self-esteem of leaders in Singapore construction sector. Construction Management and Economics, 27(3), 299 313.

Treviño, L. K., Hartman, L. P., \& Brown, M. (2000). Moral person and moral manager: How executives develop a reputation for ethical leadership. California management review, 42(4), 128-142.

Walumbwa, F. O., Mayer, D. M., Wang, P., Wang, H., Workman, K., \& Christensen, A. L. (2011). Linking ethical leadership to employee performance: The roles of leader-member exchange, self-efficacy, and organizational identification. Organizational Behavior and Human Decision Processes, 115(2), 204-213.

Whitener, E. M. (1998). The impact of human resource activities on employee trust. Human Resource Management Review, 7(4), 389-404.

Wu, L.-Z., Kwan, H. K., Yim, F. H.-k., Chiu, R. K., \& He, X. (2015). CEO ethical leadership and corporate social responsibility: A moderated mediation model. Journal of Business Ethics, 130(4), 819-831. 